\title{
An appeal to our government for nationwide policies in the prevention of cardiovascular disease
}

\author{
T. J. van Trier $\cdot$ N. Mohammadnia $\cdot$ M. Snaterse $\cdot$ R. J. G. Peters $\cdot$ H. T. Jørstad $\cdot$ W. A. Bax $\cdot$ J. D. Mackenbach
}

Accepted: 27 July 2021 / Published online: 4 October 2021

(C) The Author(s) 2021

\begin{abstract}
The high prevalence and burden of cardiovascular diseases (CVD) is largely attributable to unhealthy lifestyle factors such as smoking, alcohol consumption, physical inactivity and unhealthy food habits. Prevention of CVD, through the promotion of healthy lifestyles, appears to be a Sisyphean task for healthcare professionals, as the root causes of an unhealthy lifestyle lie largely outside their scope. Since most lifestyle choices are habitual and a response to environmental cues, rather than rational and deliberate choices, nationwide policies targeting the context in which lifestyle behaviours occur may be highly
\end{abstract}

Supplementary Information The online version of this article (https://doi.org/10.1007/s12471-021-01628-w) contains supplementary material, which is available to authorized users.

T. J. van Trier $(\bowtie) \cdot$ R. J. G. Peters · H. T. Jørstad Department of Cardiology, Amsterdam University Medical Centre, University of Amsterdam, Amsterdam, The Netherlands

t.j.vantrier@amsterdamumc.nl

N. Mohammadnia $\cdot$ W. A. Bax

Department of Internal Medicine, Northwest Clinics, Alkmaar, The Netherlands

N. Mohammadnia $\cdot$ W. A. Bax

Vascular Research Alkmaar, Alkmaar, The Netherlands

N. Mohammadnia

Department of Cardiology, Northwest Clinics, Alkmaar, The Netherlands

\section{Snaterse}

Centre of Expertise Urban Vitality, Faculty of Health, Amsterdam University of Applied Sciences, Amsterdam, The Netherlands

\section{J. D. Mackenbach}

Department of Epidemiology and Data Science, Amsterdam Public Health Research Institute, Amsterdam UMC, location VUmc, Amsterdam, The Netherlands effective in the prevention of CVD. In this point-ofview article, we emphasise the need for government policies beyond those mentioned in the National Prevention Agreement in the Netherlands to effectively reduce the CVD risk, and we address the commonly raised concerns regarding 'paternalism'.

Keywords Lifestyle - Health behaviour - Public health · Preventive medicine · Government $\cdot$ Smokefree policy

\section{Introduction}

Despite improvements in the detection and treatment of cardiovascular disease (CVD), CVD remains the leading contributor to the burden of disease in the Netherlands and worldwide. Dietary risks, tobacco use, alcohol consumption and low physical activity are ranked in the top 12 modifiable risk factors for CVD, which have barely changed since 1990 [1]. The high prevalence, disease burden and socio-economic inequalities in CVD, and the prominent role of an unhealthy lifestyle [1, 2], call for an increased focus on the prevention of CVD. Yet, in an environment that promotes the consumption of alcohol, cigarette smoking, sedentary behaviours and overeating, the promotion of a healthy lifestyle by individual healthcare professionals is a Sisyphean task (Fig. 1).

Healthcare professionals are confronted with the results of an unhealthy lifestyle on a daily basis, but their impact on lifestyle modification is limited and temporary. Along with the opportunity to influence individual lifestyles, physicians are typically called upon as 'firefighters' when prevention has failed, for example when stenting a coronary artery occlusion causing acute myocardial infarction. In addition to addressing the end stage of lifestyle-related disease, such as acute coronary syndrome, we now call upon 


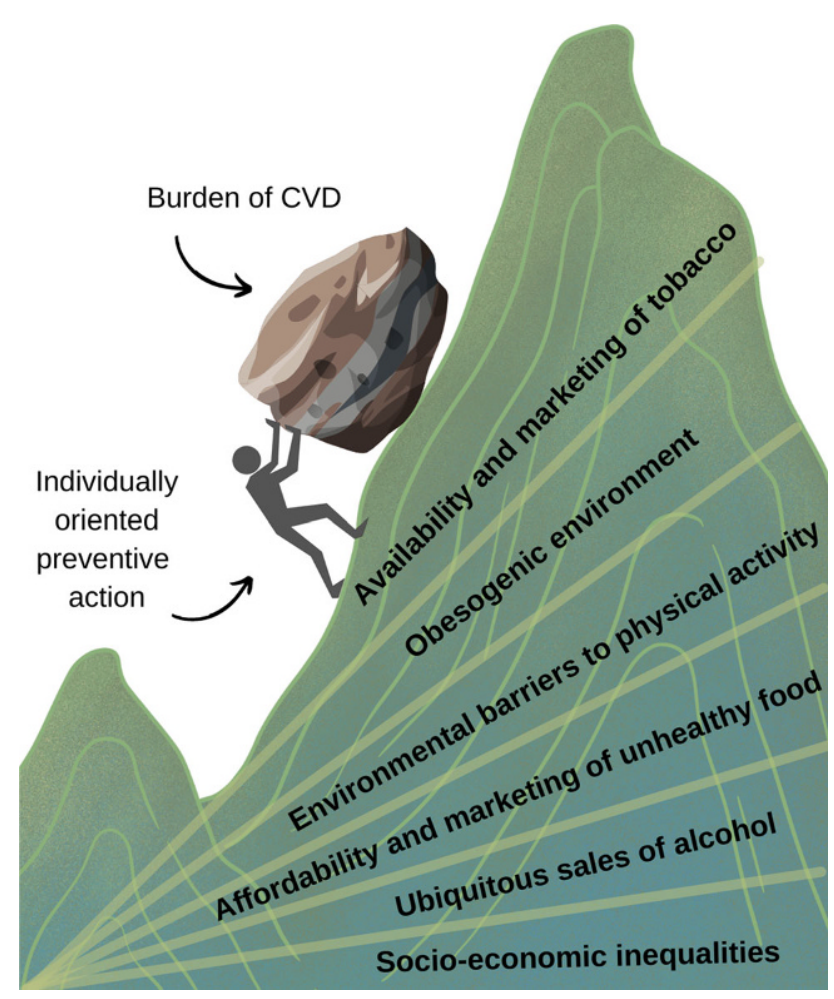

Fig. 1 The laborious and unrewarding task of promoting healthy lifestyle in an atherogenic environment can be symbolised as a Sisyphean task. Adapted from 'The health gradient' [36]

the government to address the root causes of lifestyle behaviour through policies that promote and sustain a population-wide healthier lifestyle [3, 4]. In other words, rather than strengthening the muscles of Sisyphus to push the rock up the hill, we should metaphorically flatten the hill.

However, population-level preventive policies are beyond the influence of healthcare professionals. Primordial prevention (which involves preventing the development of risk factors for disease), primary prevention (which requires modifying existing risk factors to prevent the development of disease) and even secondary prevention (to prevent progression or recurrence of disease) all take place largely outside the healthcare sector. Ideally, collaborative action should be taken by stakeholders, including industry. However, due to misalignment of interests (profit vs public good), the involvement of commodity industries in policy making often results in paradoxical policy inertia [5]. Upstream, population-wide interventions therefore mainly depend on government action [6]. This corresponds to the notion that the government is obliged by Article 22 of Dutch constitutional law to promote public health for its citizens. A well-known example of such government-level, nationwide intervention can be found in North Karelia, where an $84 \%$ reduction in coronary mortality was achieved through long-term, population-based intervention strategies such as reducing the salt content of food and a ban on tobacco advertising [7]. In this point-of-view article, we describe examples of government policies that may effectively contribute to the prevention of CVD, ranging from 'softer' policies (steering measures) to 'harder' policies (taxes and bans). These populationbased policies may affect the whole spectrum of individuals at risk for CVD, which is why we refrain from making a distinction between different stages of prevention from this point onwards. We conclude by addressing the commonly raised concern regarding 'paternalism' with respect to government intervention in public health.

\section{'Soft' policies}

Health education may engage individuals in healthy behaviour, just as dentists succeeded in promoting tooth brushing. Mass media campaigns have been used widely to reduce alcohol and tobacco consumption and to promote healthy food habits and physical activity. A Cochrane review concluded that mass media campaigns can effectively contribute to reducing smoking rates in adults, although evidence was obtained from studies of variable quality [8]. A US food policy model suggested that a 1-year mass media campaign in 2015 targeting fruit and vegetable consumption would prevent 18,600 CVD deaths by 2030 (95\% confidence interval (CI): 17,600-19,500) [9]. The main advantage of mass media campaigns is the ability to reach a large population repeatedly over time at low cost. However, poor design, limited exposure or addressing the wrong behaviour may limit their impact [10]. Also, health education and mass media campaigns require individual action, which limits their success in those in lower socio-economic positions. There is evidence that suggests that 'social marketing' or 'health branding' approaches-i.e. using marketing principles to promote healthy choices-may be effective in supporting healthy eating, although robust evaluations are lacking [11]. In this context, the European Tobacco Products Directive (2014/40/EU) requires health warnings on tobacco products. The use of nutritional or warning labels, mandatory or not, may contribute to healthier food and beverage intake and lower alcohol and tobacco consumption, although this depends on the type and positioning of the label. For example, $3.4 \%$ of all diet-related noncommunicable disease mortality is estimated to be avoidable when the 'Nutri-Score' is used as a front-ofpack nutrition label, while this would be only $1.6 \%$ for the 'Multiple Traffic Light' label [12].

Choice architecture [13] or nudging [14] interventions are gaining popularity, since their liberty-preserving character is well aligned with the current neoliberal political climate in the Netherlands. Nudging interventions such as stair prompts [15] (e.g. through directional footprints on the floor) and repositioning healthy foods or making them more salient [16] may have modest effects on cardiovascular risk fac- 
tors, yet clinical outcome data are lacking. Another 'soft' opportunity lies in the use of individual financial incentives to promote a healthy lifestyle. For instance, smoking cessation programmes based on obtaining rewards are considered acceptable, although programmes based on the possibility of losing a deposit may be more efficacious [17]. Yet, the effects of such financial incentives on promoting physical activity appear to be limited [18].

\section{‘Hard’ policies}

The 'soft' policies mentioned above compete with advanced marketing and sales of unhealthy commodity industries. For instance, considering the deadly and addictive design of cigarettes, stronger policies such as taxes, advertising and sales bans are necessary to counteract the commercial push. Comprehensive advertising bans in various settings (schools, hospitals, restaurants) have been associated with significant reductions in smoking rates [19]. As part of the National Prevention Agreement in the Netherlands, the visible display of tobacco products in stores has not been allowed since 2020. Still, the Dutch Institute for Public Health and the Environment concluded that additional measures on top of the National Prevention Agreement are needed to protect children and pregnant women from the harmful effects of smoking [20]. Institutional smoking bans have also led to reduced smoking rates in hospitals (odds ratio (OR) 0.76; 95\% CI: 0.69-0.81) and universities (OR 0.72; 95\% CI: $0.64-0.80$ ) [21]. In prisons, there was a $9 \%$ reduction in smoking-related mortality (incidence ratio $0.91 ; 95 \%$ CI: 0.88-0.95) [22]. The smoke-free legislation in the United Kingdom-prohibiting smoking in all enclosed public areas and workplaces-has contributed to an estimated 1200 fewer hospital admissions for myocardial infarctions in the 1st year [23].

In 1776, Adam Smith noted that 'sugar, rum and tobacco are commodities which are nowhere necessaries of life ... which are ... objects of almost universal consumption, and which are therefore extremely proper subjects of taxation' [24]. Currently, substantial and regular increases in the price of tobacco products are considered the most effective policy measure to reduce smoking, including in people in low socioeconomic positions $[25,26]$. Similarly, higher alcoholic beverage tax is associated with lower alcohol consumption, as regards both frequency and intensity [26], and sugar-sweetened beverage taxation reduces sugar-sweetened beverage sales [27]. The same US food policy model that estimated the impact of a mass media campaign suggested that a $10 \%$ reduction in the price of fruit and vegetables would prevent 153,300 CVD deaths (95\% CI: 146,400-159,200) [9]. While neither a subsidy on fruit and vegetables nor a sugar-sweetened beverage tax is currently included in the National Prevention Agreement in the Netherlands [20], the National Institute for Public Health and the Environment listed them as a top priority for additional measures in the prevention of obesity and associated chronic diseases [28]. A simulation study in the United Kingdom estimated that prohibiting television advertising of unhealthy foods and beverages during daytime would result in 40,000 fewer children with obesity, ultimately possibly averting the loss of 240,000 disability-adjusted life years [29]. Finally, more intense alcohol licensing policies can contribute to a $5 \%$ reduction in alcohol-related admission rates [30].

\section{Government interference vs freedom of choice}

The extent to which governments interfere may depend on the political climate. The present neoliberal climate in the Netherlands relies on the market as a social ordering mechanism, assuming that, within a market, people are free and capable to make their own choices. In this climate, 'softer' approaches may be more attractive than their 'harder' counterparts, since taxes and bans are frequently perceived as infringements on personal freedom. The tension between personal freedom and promoting public health has been debated since the 19th century, when government control over local water and sewage systems and the prohibition of drinking in pubs by children was derided as 'paternalistic' and 'despotic' [31]. Nowadays, government public health policies such as mandatory seat belts, scooter helmets and age limits for alcohol and tobacco use are widely accepted. The governmental impact on public health is currently highlighted by the measures taken during the COVID19 pandemic. When danger is as obvious as in this pandemic, actions taken by authorities to protect their citizens are widely accepted-even though the disease burden of COVID-19 is clearly lower than that of CVD. Incorrectly, the urgency of CVD may be perceived as low since 'danger' is slow and perhaps more familiar. In addition, instead of framing government interference as a loss of individual freedom, it can also be seen as protecting individual freedom that would otherwise be manipulated by the influence of the unhealthy commodity industry $[32,33]$. In fact, most lifestyle choices are made habitually and in response to environmental cues [34], prompted by actors less concerned about population (and individual) health. This is especially important in socio-economically deprived groups, where lifestyle 'choices' are frequently constrained by limited resources [33, 35].

In conclusion, there is convincing evidence for the effectiveness of government policies resulting in the prevention of CVD. Population-level interventions targeting the context in which lifestyle behaviour develops are especially promising, facilitating the initiation of and adherence to a healthy lifestyle. Although healthcare professionals will remain on call as firefighters, we simultaneously call upon the government to take its responsibility to prevent fires. 
Conflict of interest T.J. van Trier, N. Mohammadnia, M. Snaterse, R.J.G. Peters, H.T. Jørstad, W.A. Bax and J.D. Mackenbach declare that they have no competing interests.

Open Access This article is licensed under a Creative Commons Attribution 4.0 International License, which permits use, sharing, adaptation, distribution and reproduction in any medium or format, as long as you give appropriate credit to the original author(s) and the source, provide a link to the Creative Commons licence, and indicate if changes were made. The images or other third party material in this article are included in the article's Creative Commons licence, unless indicated otherwise in a credit line to the material. If material is not included in the article's Creative Commons licence and your intended use is not permitted by statutory regulation or exceeds the permitted use, you will need to obtain permission directly from the copyright holder. To view a copy of this licence, visit http://creativecommons.org/licenses/by/4.0/.

\section{References}

1. Roth GA, Mensah GA, Johnson CO, et al. Global burden of cardiovascular diseases and risk factors, 1990-2019: update from the GBD 2019 study. J Am Coll Cardiol. 2020;76:2982-3021.

2. Mejean C, Droomers M, van der Schouw YT, et al. The contribution of diet and lifestyle to socioeconomic inequalities in cardiovascular morbidity and mortality. Int J Cardiol. 2013;168:5190-5.

3. Rose G. Sick individuals and sick populations. Int J Epidemiol. 1985;14:32-8.

4. Emberson J, Whincup P, Morris R, Walker M, Ebrahim S. Evaluating theimpact of population andhigh-riskstrategies for the primary prevention of cardiovascular disease. Eur Heart J.2004;25:484-91.

5. Swinburn BA, Kraak VI, Allender S, et al. The global syndemic of obesity, undernutrition, and climate change: the Lancet commission report. Lancet. 2019;393:791-846.

6. Lakerveld J, Mackenbach J. The upstream determinants of adult obesity. Obes Facts. 2017;10:216-22.

7. Vartiainen E. The North Karelia Project: cardiovascular disease prevention in Finland. Glob Cardiol Sci Pract. 2018;2018:13.

8. Bala MM, Strzeszynski L, Topor-Madry R. Mass media interventions for smoking cessation in adults. Cochrane Database Syst Rev. 2017;11:CD4704.

9. Pearson-Stuttard J, Bandosz P, Rehm CD, et al. Comparing effectiveness of mass media campaigns with price reductions targeting fruit and vegetable intake on US cardiovascular disease mortality and race disparities. AmJClin Nutr. 2017;106:199-206

10. Wakefield MA, Loken B, Hornik RC. Use of mass media campaigns to change health behaviour. Lancet. 2010;376:1261-71.

11. Englund TR, Zhou M, Hedrick VE, Kraak VI. How branded marketing and media campaigns can support a healthy diet and food well-being for Americans: evidence for 13 campaigns in the United States. J Nutr Educ Behav. 2020;52:87-95.

12. Egnell M, Crosetto P, d'AlmeidaT, etal. Modellingtheimpact of different front-of-package nutrition labels on mortality from non-communicable chronic disease. Int J Behav Nutr Phys Act. 2019;16:56.

13. Hollands GJ, Bignardi G, Johnston M, et al. The TIPPME intervention typology for changing environments to change behaviour. Nat Hum Behav. 2017;1:140.
14. Thaler RH, Sunstein CR. Nudge: improving decisions about health, wealth, and happiness. New Haven, CT: Yale University Press; 2008.

15. Landais LL, Damman OC, Schoonmade LJ, Timmermans DRM, Verhagen E, Jelsma JGM. Choice architecture interventions to change physical activity and sedentary behavior: a systematic review of effects on intention, behavior and health outcomes during and after intervention. Int J Behav Nutr Phys Act. 2020;17:47.

16. Harbers MC, Beulens JWJ, Rutters F, et al. The effects of nudges on purchases, food choice, and energy intake or content of purchases in real-life food purchasing environments: a systematic review and evidence synthesis. Nutr J. 2020;19:103.

17. Halpern SD, FrenchB, SmallDS, Saulsgiver K, etal. Randomized trial of four financial-incentive programs for smoking cessation. NEngl J Med. 2015;372:2108-17.

18. Luong MN, Hall M, Bennell KL, Kasza J, Harris A, Hinman RS. Theimpact of financial incentives on physical activity: a systematic review and meta-analysis. Am J Health Promot. 2021;35:236-49.

19. Flor LS, Reitsma MB, Gupta V, Ng M, Gakidou E. The effects of tobacco control policies on global smoking prevalence. NatMed. 2021;27:239-43.

20. Rijksinstituut voor Volksgezondheid en Milieu. Quickscan mogelijkeimpact Nationaal Preventieakkoord. RIVM;2018.

21. Frazer K, McHugh J, Callinan JE, Kelleher C. Impact of institutional smoking bans on reducing harms and secondhand smoke exposure. Cochrane Database Syst Rev. 2016;5:CD11856.

22. Binswanger IA, Carson EA, Krueger PM, Mueller SR, Steiner JF, Sabol WJ. Prison tobacco control policies and deaths from smoking in United States prisons: population based retrospective analysis. BMJ. 2014;349:g4542.

23. Sims M, Maxwell R, Bauld L, Gilmore A. Short term impact of smoke-free legislation in England: retrospective analysis of hospital admissions for myocardial infarction. BMJ. 2010;340:c2161.

24. Smith A. An inquiry into the nature and causes of the wealth of nations. London: W. Strahan and T. Cadell; 1776.

25. Brown T, Platt S, Amos A. Equity impact of populationlevelinterventions and policies to reduce smokingin adults: a systematic review. DrugAlcohol Depend. 2014;138:7-16.

26. Chaloupka FJ, Powell LM, Warner KE. The use of excise taxes to reduce tobacco, alcohol, and sugary beverage consumption. Annu Rev Public Health. 2019;40:187-201.

27. Backholer K, Sarink D, Beauchamp A, et al. The impact of a tax on sugar-sweetened beverages according to socioeconomic position: a systematic review of the evidence. Public Health Nutr. 2016;19:3070-84.

28. van Giessen A, Douma E, Kuijpers T, et al. Inventarisatie aanvullende maatregelen Nationaal Preventieakkoord. Rijksinstituut voor Volksgezondheid en Milieu (RIVM); 2021.

29. Mytton OT, Boyland E, Adams J, et al. The potential health impact of restricting less-healthy food and beverage advertising on UKtelevision between 05.30 and 21.00 hours: a modelling study. PLoS Med. 2020; https://doi.org/10. 1371/journal.pmed.1003212.

30. deVochtF, Heron J, Angus C, etal. Measurable effects oflocal alcohol licensing policies on population health in England. JEpidemiol Community Health. 2016;70:231-7.

31. Jochelson K. Nanny or steward? The role of government in public health. Public Health. 2006;120:1149-55.

32. Moore M, Yeatman H, Davey R. Which nanny-the state or industry? Wowsers, teetotallers and the fun police in public health advocacy. Public Health. 2015;129:1030-7. 


\section{Point of View}

33. Kahneman D. Thinking, fast and slow. Fortune. 2015;172:363-74.

34. Strack F, Deutsch R. Reflective and impulsive determinants of social behavior. Pers Soc Psychol Rev. 2004;8:220-47.

35. Adams J, Mytton O, White M, Monsivais P. Correction: why aresomepopulationinterventionsfordietand obesitymore equitable and effective than others? The role of individual agency. PLoS Med. 2016;13:e1002045.

36. Taket AR. Making partners: intersectoral action for health. Copenhagen: World Health Organization; 1990. 